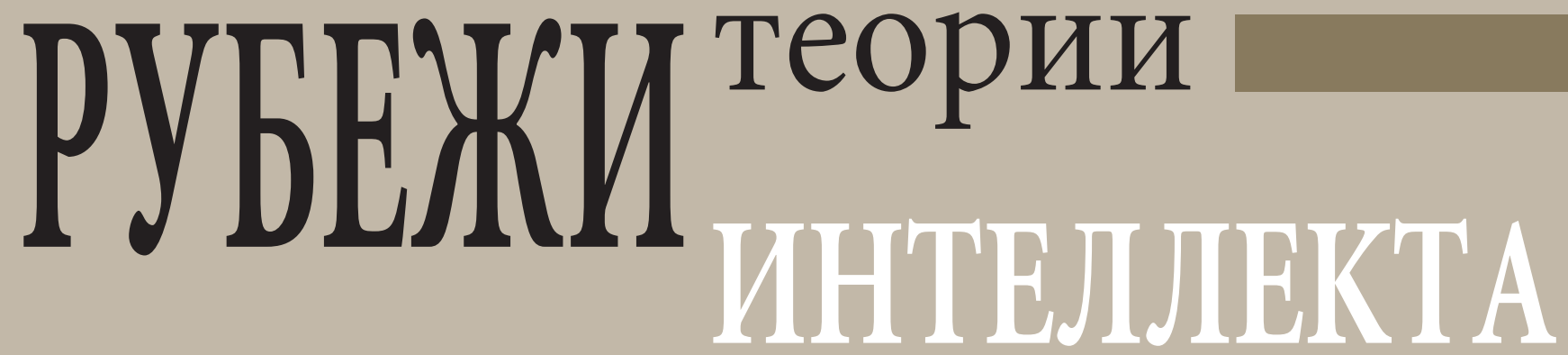

\title{
М. Энтони
}

Общепринятая теория интеллекта развивается преимущественно в рамках рационального критического мировоззрения. Чаще всего обсуждаются психометрическая и системная теории интеллекта. Однако предметом настоящей статьи являются некоторые более перспективные теории, которые, оставаясь в рамках традиционных научных представлений, описывают, в частности, эмоциональный, креативный, внутриличностный интеллект и мудрость. Конечно, возможны и другие представления об интеллекте. Среди них, например, интегральный интеллект - концепция, в которой признается и эффективно используется представление о межличностных потенциалах разума. Это альтернативная теория, и в данной статье общепринятые теории анализируются, сравниваются и противопоставляются именно теории интегрального интеллекта. Рассматривается вопрос о том, как отразится на будущем дискурса по теории интеллекта возможное признание интегрального интеллекта. 
Отныне и в будущем особо востребованными станут те, кто способен широко мыслить, взаимодействовать с другими, рассматривать многочисленные варианты последствий, представлять альтернативные решения и творчески решать проблемы [1, с. 108].

$\mathrm{P}$ едкие области психологии остаются столь спорными и проблематичными, как теория интеллекта. Стернберг, Лотри и Лубарт отмечают, что первопричина этого в «несовершенстве инструментов», применяемых исследователями [2, с. 3]. Расхождения в идеологии и определениях понятия «интеллект» огромны. Например, Кэрролл и Гарднер, обосновывая свои теории интеллекта, опираются на почти не пересекающиеся наборы исторических данных [там же] ${ }^{1}$.

И эта проблема лишь один из примеров, подтверждающих тот факт, что в области теории интеллекта для футурологов и специалистов по Форсайту существует широкое поле для исследований и дискуссий. Как известно, интеллект сам по себе с трудом поддается определению и количественной оценке (если он вообще может быть измерен количественно). Существуют эпистемологические вопросы, сосредоточенные вокруг цивилизационных и культурных медиаторов, влияющих на характер дискурса. По сути, то, как мы воспринимаем интеллект, измеряем его, рассуждаем о нем, используем его в наших школах, обществе и в частной жизни, сильно зависит от взаимодействия медиаторов. К сожалению, многие важные аспекты человеческого интеллекта забыты, скрыты или исключены из рассмотрения в доминирующем научном дискурсе. Это касается, в частности, концепции интегрального интеллекта [3], которая восходит к мистическому/духовному мировоззрению2 ${ }^{2}$ В нашей статье концепция интегрального интеллекта будет использоваться как для расширения параметров дискурса, так и для расшатывания общепринятых доминирующих теорий интеллекта.

Данная работа преследует несколько целей. Во-первых, я кратко охарактеризую ранее упомянутые медиаторы. Во-вторых, дам определение интегрального интеллекта. Также я опишу и проанализирую четыре теории интеллекта, которые представляются наиболее прогрессивными в рамках современной парадигмы, и прокомментирую их совокупное значение для развития доминирующего дискурса в вопросе об интеллекте. Наконец, позволю себе обратить взгляд в будущее и попробую предсказать возможное направление и содержание этого дискурса при включении в него интегрального интеллекта.
На различных этапах работы я прибегаю к помощи многослойного причинного анализа (causal layered analysis - CLA) Сохаила Инаятулла [4]. CLA - постструктуралистская методология, которая исследует глубинные смыслы, заложенные в текстах посредством анализа на четырех уровнях. Эта методология признает иные пути познания. Первый компонент CLA исследует анамнез $3^{3}$, т.е. рациональные/научные, фактические и количественные аспекты текста. Второй компонент CLA охватывает соииальный и системный уровень. Он вскрывает экономические, культурные, политические и исторические аспекты. Третий элемент CLA раскрывает дискурс/миробоззрение автора. На этом уровне выявляются сделанные автором допущения и предпринимается попытка различить глубинные социальные, лингвистические и культурные структуры, которые проявляются в его индивидуальном восприятии реальности. Это позволяет обнажить картину реальности, лежащую в основе работы автора. Последний слой - мифический/метафорический уровень. Здесь анализ стремится выявить скрытые и явные мифы, сюжеты, символы и метафоры, используемые в тексте. На этом уровне могут находиться эмоциональные, бессознательные и архетипические компоненты. Многослойный причинный анализ особенно полезен как метод исследования, способствующий проникновению в природу прошлого, настоящего и будущего. Таким образом, можно открыть настоящее и прошлое навстречу возможностям альтернативных вариантов будущего [там же].

\section{Теория интеллекта}

Есть много способов классифицировать теории интеллекта. Два основных подхода к интеллекту, которые я буду использовать ниже, восходят к отчетливо различимым первоисточникам. Это - психометрическая и системные теории 4 .

Теории коэффициента умственного развития (IQ) и общего интеллекта относятся к числу психометрических моделей интеллекта. Психометрическоеисследование всецело зависит от факторного анализа, и главный упор в нем делается на измерении общего интеллекта. В основе этой области лежат ранние работы Фрэнсиса Гальтона, но наиболее серьезное влияние на нее оказала двухфакторная теория интеллекта, предложенная британским физиологом Чарльзом Спирманом в начале XX столетия [6]. Под влиянием Спирмана находятся и современные теоретики Йенсен, Айзенк, Хернстайн и Мёрри $[7,8,9]$.

В то же время теории внутриличностного интеллекта Гарднера $[10,11]$, эмоционального интеллекта Гоулмена [12] и Саловея и Пицарро [13] являются сис-

\footnotetext{
${ }^{1}$ В одной статье можно представить лишь малую часть многочисленных и разнообразных теорий и дискуссий, из которых складывается современная теория интеллекта. Обзор всех этих дебатов не входит в задачи данной работы.

${ }^{2}$ Мистический духовный подход к знанию основывается на слиянии «Я» и «другого», познающего и познаваемого. Эта идея берет начало в мистическом/духовном мировоззрении. Интуиция является ключевым методом познания. Критическая рациональность - это преимущественно западный подход к познанию, основанный на логике, рассуждении и научном методе. Он возникает в рамках критического/рационального мировоззрения. Ключевыми методами познания являются: классификация, анализ, эксперимент, а также вербальный/лингвистический и математический/логический интеллекты [3].

${ }^{3}$ Сохаил Инаятулла обозначает первый уровень модели CLA термином «litany», однако его дословный перевод на русский язык не вполне адекватен. Термин «анамнез» точнее отражает суть первого уровня, на котором осуществляются сбор и систематизация разнородной фактической и оценочной информации о фактах, событиях и тенденциях в предметной области. Подробнее с описанием CLA можно ознакомиться на сайте Сохаила Инаятулла www. metafuture. org [npuм. peд.].

${ }^{4}$ Более точную схему исторического развития теории интеллекта можно найти у Плакера [5]. Он очерчивает основные линии развития и отношения между ними и стоящими за ними теоретиками.
} 


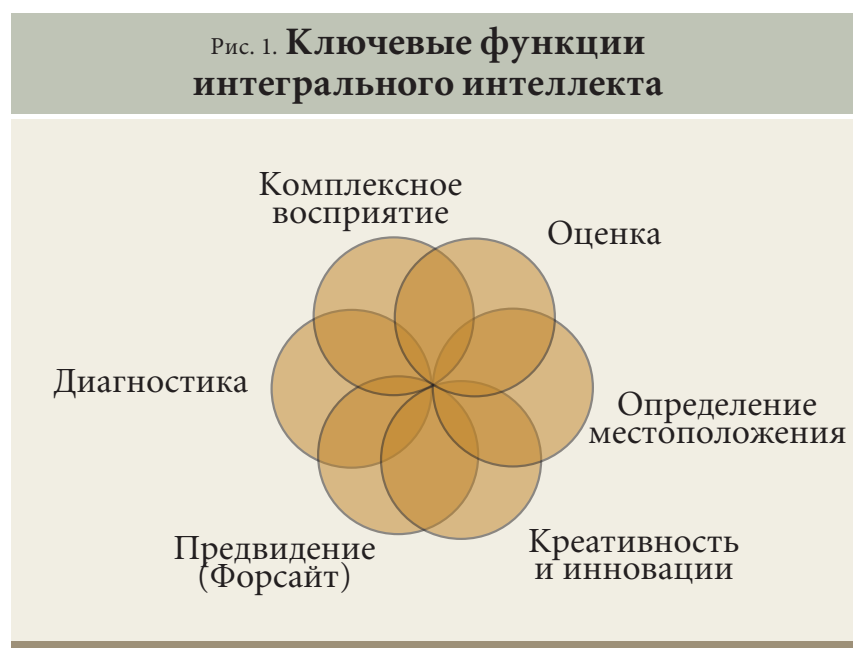

темными моделями интеллекта. В этих относительно молодых теориях предпринимается попытка понять интеллект с множества точек зрения [6]. Гарднер испытал сильное влияние многофакторной теории Л. Л. Терстоуна, разработанной в первой половине XX века. Концепция мудрости Канцмана и Балтеса [14] и теория креативного интеллекта Лубарта [15] также могут быть названы системными моделями, поскольку признают и включают в себя другие теории интеллекта. Однако позиционирование этих моделей в широкой сфере теории интеллекта - задача весьма сложная, если учитывать высокую степень их взаимопроникновения и дискуссионную природу самой этой области.

Я решил сосредоточиться на нескольких темах и дискуссиях, тесно связанных с идеей интегрального интеллекта. Но это приведет нас к более широким выводам об этой сфере.

Во-первых, идея общего интеллекта, или «g», рассматривается в сравнении с психометрическими моделями интеллекта. В частности, в фокусе внимания будет тенденция приравнивания общей способности того, что Гарднер называет «классическим интеллектом» $[10],-$ к критической рациональности и статистической проверяемости.

Во-вторых, после первоначального рассмотрения системных моделей мы обратимся к противопоставлению проблемно-зависимых и проблемно-независимых теорий интеллекта. Здесь соприкасаются теории пре-

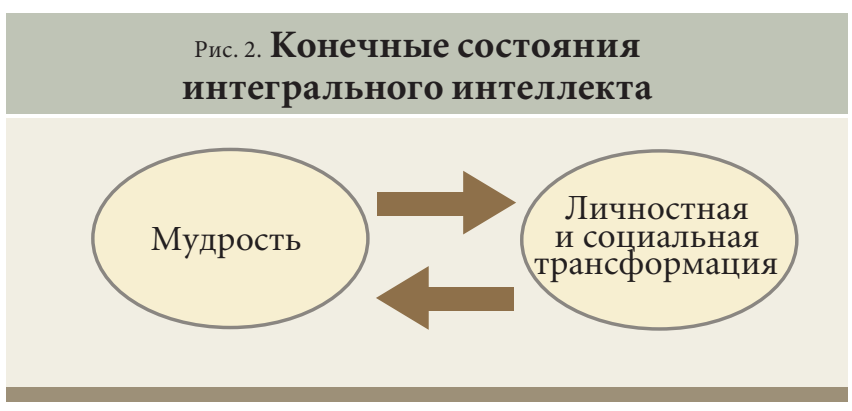

имущественно критические/рациональные (проблемно-независимые теории IQ) и другие, включающие более широкие когнитивные модальности (проблемно-зависимые теории). В обсуждении подчеркивается ряд ограничений, присущих обоим подходам. В следующем разделе интегральный интеллект сравнивается и противопоставляется четырем вышеуказанным системным теориям. В конце приводится ряд выводов, касающихся интегрального интеллекта и современной общепринятой теории интеллекта.

\section{Интегральный интеллект}

В этой статье я постоянно обращаюсь к понятию интегрального интеллекта и стоящей за ним теории 5 . Интегральный интеллект - это преднамеренное и сознательное использование расширенного разума таким образом, чтобы обеспечить успешную деятельность индивидуума в данной внешней среде.

В свою очередь, расширенный разум определяется как состояние персонального сознания, в котором индивидуальное понимание соединяется с надличностным, выходящим за пределы разума индивидуума и его сенсорных органов.

Термин «расширенный разум» заимствован у Руперта Шелдрейка [17]. Термин «интегральный интеллект»- мой собственный. Еще одно важное различие заключается в том, что «интегральный разум» противопоставляется «фрагментированному разуму». Интегральный разум - это человеческий разум, осознающий свою духовную и надличностную базу знаний, в то время как фрагментированный разум представляет собой состояние когнитивной способности, в котором указанное осознание не развито.

\section{Таблица 1. Основные операции интегрального интеллекта}

\begin{tabular}{|c|c|}
\hline Когнитивный процесс & Содержание и сферы потенциального применения \\
\hline Комплексное восприятие & $\begin{array}{l}\text { Целостное восприятие порядка и смысла, лежащих в основе систем (включая космос), а также } \\
\text { заключенного в них «интеллекта». Усиление «духовного» мировоззрения; значение и смысл отно- } \\
\text { шений с природой и космосом }\end{array}$ \\
\hline $\begin{array}{l}\text { Определение } \\
\text { местоположения }\end{array}$ & $\begin{array}{l}\text { Определение местоположения важных объектов [21, с. 139-141]; локализация информации и дан- } \\
\text { ных для исследования; идентификация релевантных людей и мест }\end{array}$ \\
\hline Диагностика & $\begin{array}{l}\text { Диагностика медицинских и технических проблем, угрозы безопасности, здоровью и окружающей } \\
\text { среде; источников человеческих ошибок }[21, \text { c. 141]. Духовный и психологический самоанализ. }\end{array}$ \\
\hline Оценка/выбор & $\begin{array}{l}\text { Оценка альтернативных вариантов конструкции и дизайна, выбор направления инвестиций, } \\
\text { исследовательской стратегии, технологических альтернатив [21, с. 139]. Оценка жизни, карьеры } \\
\text { и выбор партнеров }\end{array}$ \\
\hline Предвидение (Форсайт) & $\begin{array}{l}\text { Предвидение природных бедствий, политических условий, развития технологий, факторов дете- } \\
\text { риорации, инвестиционных возможностей [21, с. 142]. Определение последствий выбора }\end{array}$ \\
\hline $\begin{array}{l}\text { реативность и } \\
\text { нновации }\end{array}$ & $\begin{array}{l}\text { Индивидуум обращается к надличностным режимам сознания для стимулирования своего вдох- } \\
\text { новения и творческой продуктивности в работе, бизнесе, исследованиях, соревнованиях и досуге }\end{array}$ \\
\hline
\end{tabular}

${ }^{5}$ За более развернутым объяснением концепции и теории интегрального интеллекта читателю следует обратиться к моей книге по этому предмету [3]. Краткий очерк можно найти в других моих статьях, доступных в интернете $[18,19,20]$, см. также www. mindfutures. com. 


\section{Таблица 2. Конечные состояния интегрального интеллекта}

Когнитивный процесс

Мудрость

\section{Личностная и}

социальная

трансформация
Потенциальне применение

Интуитивно понимая причины, смысл и функции, лежащие в основе различных жизненных процессов, индивидуум способен делать интеллектуальный выбор, который способствует счастью, благосостоянию и духовному развитию как его самого, так и коллектива

Оптимальная человеческая и космическая эволюция. Может включать в себя аспекты всех основных операций, направленных на оценку личных целей и решений в масштабах планетарной и космической динамики. Потенциал для роста надежды и смысла
Концепция интегрального интеллекта предполагает шесть когнитивных измерений (основных операций) и два конечных состояния. Эти основные операции показаны на рисунках 1 и 2. В таблицах 1 и 2 основные операции и конечные состояния описаны подробнее, включая потенциальное применение.

\section{Позиционирование интегрированного интеллекта}

С точки зрения постструктуралистского и критического взгляда в будущее ясно, что классические психология и теория интеллекта опираются на западные цивилизационные и эпистемологические предпосылки. На рисунке 3 представлена схема, которая выявляет главную причину исключения мистических/духовных концепций и теорий из современной западной науки о разуме. Следует выйти за пределы этих ограничений, связанных с физической очевидностью. Для чего - объяснено на рисунке 3 , который позиционирует теорию интеллекта в рамках цивилизационной, парадигматической и культурной перспективы. Каждый уровень определяется и поддерживается нижележащим уровнем. Такое расположение отражает то, как дискурсы по интеллекту и разуму поднимаются с уровня на уровень и в конечном счете определяются самым нижним уровнем системы: всепроникающим уровнем сознания - визуальной логикой [22].

На рисунке 3 показана сложившаяся гегемония рационализма, доминирующего пока в традиционной науке о разуме на Западе. Именно в рамках этой гегемонии найти место для концепции интегрального интеллекта весьма трудно 6 .

\section{Критика теории g-фактора и проблемно-зависимых теорий}

В профессиональной сфере непризнание концепции интегрального интеллекта в рамках общепринятого научного дискурса может быть отчасти объяснено влиянием концепции проблемно-независимого интеллекта IQ. Рациональная и абстрактная концепция IQ в конечном счете интегрирована в критическое/рациональное мировоззрение, и, в свою очередь, предпочтительный для этой концепции путь познания сосредоточен на критической рациональности ${ }^{7}$.

Имеется убедительное свидетельство в поддержку того, что концепция IQ принципиально ошибочна. Основным аргументом в пользу проблемно-независимого интеллекта являются сильные корреляции когнитивных способностей, измеренных в различных тестах на интеллект [7, 23]. Например, все категории в тестировании интеллекта по методу WAIS-3 имеют корреляции, которые указывают на существование g-фактора. Люди, показавшие высокие результаты в любом из тринадцати тестовых компонентов, склонны демонстрировать подобные результаты и в остальных двенадцати [23, с. 8].

Сильная связь между интеллектом и генетикой - еще одно свидетельство в пользу представления о g-факторе. Изучение однояйцевых близнецов, выросших вместе и раздельно, обнаружило минимальные различия в оценках по тесту IQ, а значит, внешняя среда лишь отчасти влияет на значение IQ [23]. Например, миннесотское исследование разделенных близнецов показало, что вклад среды в IQ составляет около 30\% $[23$, c. 72$]$. Сам Дири приходит к выводу, что «примерно на 50\%» интеллект определяется факторами внешней среды и в той же степени генетическими факторами [23, с. 74].

Важно, что методы доказательства, используемые этими теоретиками при обсуждении психометрических подходов к интеллекту, систематически и парадигматически ограничены. Здесь доминируют математический/логический и экспериментальный пути познания - такова специфика данной области.

Многие приводят доводы против сложившегося представления о g-факторе. Найссер считает, что тесты на интеллект измеряют способности к науке в противоположность практическому складу ума. Нэш [24] утверждает, что тесты на IQ серьезно дискредитированы в современной науке о психологических испытаниях и измерениях и котируются не выше, чем «имеющая хождение в профессиональной среде и не требующая доказательств теория “способностей”» $[24$, с. 4]. Вызов, брошенный Нэшем, основан на юридических исках против «расширительных трактовок» теории IQ, выигранных в американских судах более двух десятилетий назад [там же]. В то же время Стернберг, выполнив анализ уровня анамнеза, заключил, что фактор общего интеллекта - это «артефакт, связанный с ограниченностью подвергавшихся тестированию популяций индивидуумов, типов материалов, при помощи которых они тестировались, и применявшихся при этом методов» [25].

В середине XX столетия различные исследователи расшатывали «материалистическую» концепцию врожденного и измеримого интеллекта [26, с. 55]. В 1931 году Лионель Пенроуз в результате обширно-

\footnotetext{
${ }^{6}$ Подробнее об этой схеме и стоящем за ней историческом процессе см. [24].

${ }^{7}$ Критические/рациональные пути познания включают: классификацию, анализ, эксперимент, а также вербальный/лингвистический и математический/логический интеллекты; мистический/духовный путь познания включает классическую интуицию и инференционную интуицию (практическую), как это было показано мною
} раньше [24]; см. также [3]. 
Рис. 3. Многослойная схема, отражающая эпистемологические основы западной науки о разуме

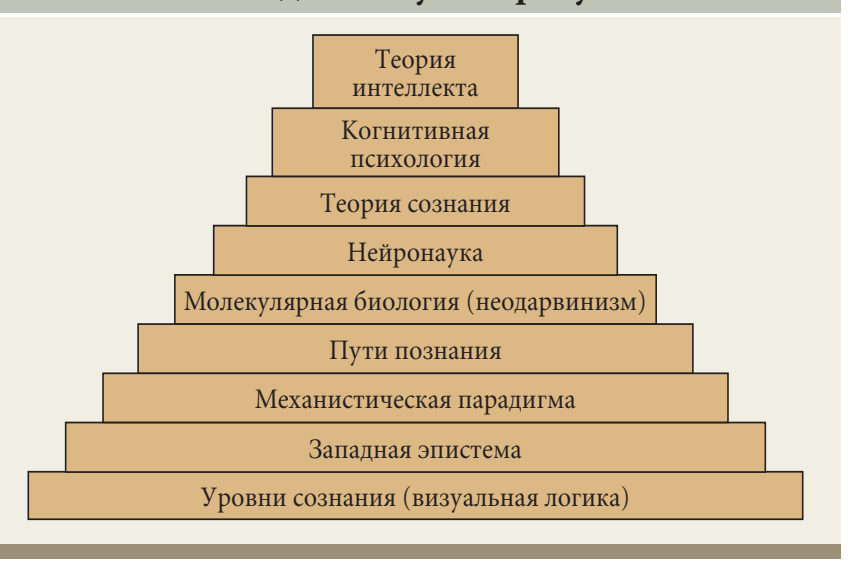

го исследования обнаружил, что существуют различные причины умственных отклонений у индивидуумов. Только 25\% из них можно было бы объяснить одной лишь наследственностью. Другие исследователи утверждали, что показатель IQ можно увеличить при наличии стимулирующей среды. В 1940-1950-х годах Д.О. Хебб обнаружил, что связь между интеллектуальной деятельностью и планированием не является непосредственной. У пациентов с поврежденными фронтальными долями мозга подавлена способность планирования в отношении места и времени, а также выдвижения новых подходов к решению проблем. Но у этих пациентов обычно не обнаруживается соответствующего снижения показателя IQ. Таким образом, исследователи показали наличие сложной взаимосвязи между интеллектом, наследственностью и окружающей средой [там же]. И что особенно важно, исследования показывают, что «измеримый интеллект не является легко интерпретируемой характеристикой» $[26$, c. 55].

Критика IQ сфокусирована на социальном уровне (воспитании) и направлена против исследований, проводимых сторонниками концепции IQ преимущественно на уровне анамнеза (природа или наследственность).

Несмотря на эту критику теории IQ, на социальном уровне фактически продолжают поддерживаться образовательные практики, порожденные существующим распределением академических заслуг [24]. Теория IQ надежно обеспечила себе долгожительство в рамках концепции «способности». Нэш находит корни долгожительства закрепившихся концепций интеллекта и способности в социологических теориях, объясняющих причины неравенства образовательных возможностей. Таким образом, в понимании Нэша теория IQ представляет собой «отживающую и не нашедшую подтверждения психологическую парадигму» [24]. Исходя из этого, можно предположить, что концептуализация интеллекта, как состоящего прежде всего из рациональных, лингвистических и математических способностей, способствует продлению жизни идеи проблемно-независимой «способности». На это указывает тот факт, что нынешние тесты способности очень похожи на традиционные тесты для определения IQ [24].

Однако следует заметить, что, несмотря на это, теория множественного интеллекта Гарднера (описанная ниже), по-видимому, все же оказала на образование большее влияние, нежели любая прежняя теория интеллекта [2]. Закрепление концепции способности на фоне растущей поддержки тезисов Гарднера среди педагогов-методистов свидетельствует о заметном расколе в образовательном сообществе. Тем не менее популярность более совместимых (с интегральным интеллектом) представлений Гарднера служит своеобразным окном, позволяющим более радикальным идеям вроде интегрального интеллекта оказывать определенное влияние на современную систему образования.

\section{Проблемно-независимый интеллект, IQ и критическая рациональность}

Дебаты относительно теории IQ, как правило, ограничены уровнем анамнеза и социальным уровнем. Ниже представлен более глубокий анализ, задействующий третий и четвертый уровни CLA.

Как отмечает Гарднер [10, 27], тестирование IQ прежде всего измеряет рациональные, математические и лингвистические когнитивные процессы и, таким образом, имеет тенденцию определять интеллект в пределах указанных сфер. Приведу примеры Термана [28, с. 128]: «индивидуум интеллектуален постольку, поскольку он способен к абстрактному мышлению»; Айзенка [8]: IQ как статистически овеществленная мера интеллекта; Йенсена [7, с. 15]: IQ-тесты измеряют «высшие умственные процессы»; и Хернстайна и Мёрри [9]: IQ описывается в рациональных, лингвистических и логических терминах и материализуется перед нами в виде кривой нормального распределения. Такие представления об интеллекте носят отчетливо критический/рациональный характер, отражая механистическую парадигму ${ }^{8}$.

Типичный пример современного тестирования интеллекта - шкала Векслера для оценки интеллекта взрослых (Wechsler Adult Intellect Scale), версия 111, или WAIS-3 [23]. Тестирование проводится в четырех общих проблемных областях, охватывающих следующие 13 компонентов:

\section{Вербальное понимание}

- словарь (значения слов)

- подобия (сходства между двумя словами)

- информация (общие знания)

- понимание (решение проблем повседневной жизни, социальных проблем; толкование пословиц)

\section{Перцептуальная организация}

- завершение картины (определение отсутствующего элемента в ряде цветовых рисунков)

- конструирование из блоков (воспроизведение двумерных узоров из блоков различных цветов)

- систематизация изображений (размещение

${ }^{8}$ Известна также как ньютоно-картезианская парадигма. Она появилась в эпоху Просвещения и представляет Вселенную как огромную машину, наполнение и процессы в которой характеризуются механическими свойствами. Ньютоновская наука обычно описывает чисто материальную Вселенную, состоящую из атомов, подчиняющихся принципам детерминизма, с фиксированными законами, которые управляются всеми явлениями в космосе, состоящем из «цепочек независимых причин и следствий» [29, с. 18-19]. 
мультипликационных образов в порядке, передающем историю)

- матрица умозаключения (обнаружение отсутствующего элемента в подборке, построенной логическим образом)

\section{Скорость обработки данных}

- поиск символа (определение, какой из двух предложенных символов содержится в заданном перечне абстрактных символов)

- цифровое кодирование символов (запись номера, соответствующего предложенному символу)

\section{Рабочая память}

- буквенно-цифровые последовательности (воспроизведение чередующихся букв и чисел с размещением их в алфавитном/числовом порядке)

- числовой охват (запоминание и повторение последовательности чисел)

- Арифметика

WAIS-3 отражает принципы критического/рационального мировоззрения и соответствующие пути познания. Вербальное понимание - это, по определению, вербальный/лингвистический процесс. Компонент «скорость обработки данных» требует поиска решений математических и лингвистических задач (линейных, вербальных, математических когнитивных процессов); того же требует и серия тестов на рабочую память. Группа «перцептуальная организация» наводит на размышления о ньютоновой, евклидовой физике (использование блоков и систематизация изображений подчеркивают временную линейность, в то время как матрица умозаключения подкрепляет логическое мышление). Особенно примечательно полное отсутствие каких-либо рефлексивных или внутриличностных когнитивных модальностей. Любой подобный когнитивный процесс, который возможно использовать в ходе тестирования WAIS-3, остается, таким образом, нераспознанным и незримым. Наконец, на социальном уровне анализа WAIS-3 - подобно многим стандартным тестам IQ - является примером письменного тестирования с участием студента и экзаменатора, что характерно для западной системы образования.

\section{IQ превозносит измеримое, интегральный интеллект - неуловимое}

Есть еще одно важное различие между теориями IQ и интегрального интеллекта. Господствующая теория (особенно теория g-фактора) зиждется на статистическом анализе - одной из наиболее сложных областей психологии [23]. Это делает знание ненадежным: «В психологии мы склонны измерять то, что поддается измерению. Поэтому, когда мы рассуждаем об умственных способностях и их взаимосвязях, необходимо ясно осознавать, что, раз есть ценные качества, которые мы не можем легко измерить, наша оценка интеллекта не будет исчерпывающей» [23, с. 1-2].

Еще раз отмечу: критический/рациональный путь познания - математический/логический интеллект - является имплицитно привилегированным. Тонкие модальности внутриличностного в такой системе невидимы.

Как ни странно, несмотря на механистический уклон концепции g-фактора, IQ сам по себе - нематериальная конструкция и является социальным изобретением [30, c. 132]. Харауэй, например, пишет, что IQ - «материализованная фикция. Это - пример аппарата для материализации мира, и такие формы - сами по себе способы доминирования. Подобные аппараты производят субъектов с различными свойствами, поддающимися измерению, например: студент с определенной оценкой или беременная девочка-подросток с характеристикой, которая ставит ее перед угрозой дальнейшего надзора... Но в данном случае мы институционально упускаем то, что мы имеем аппарат для продуцирова-

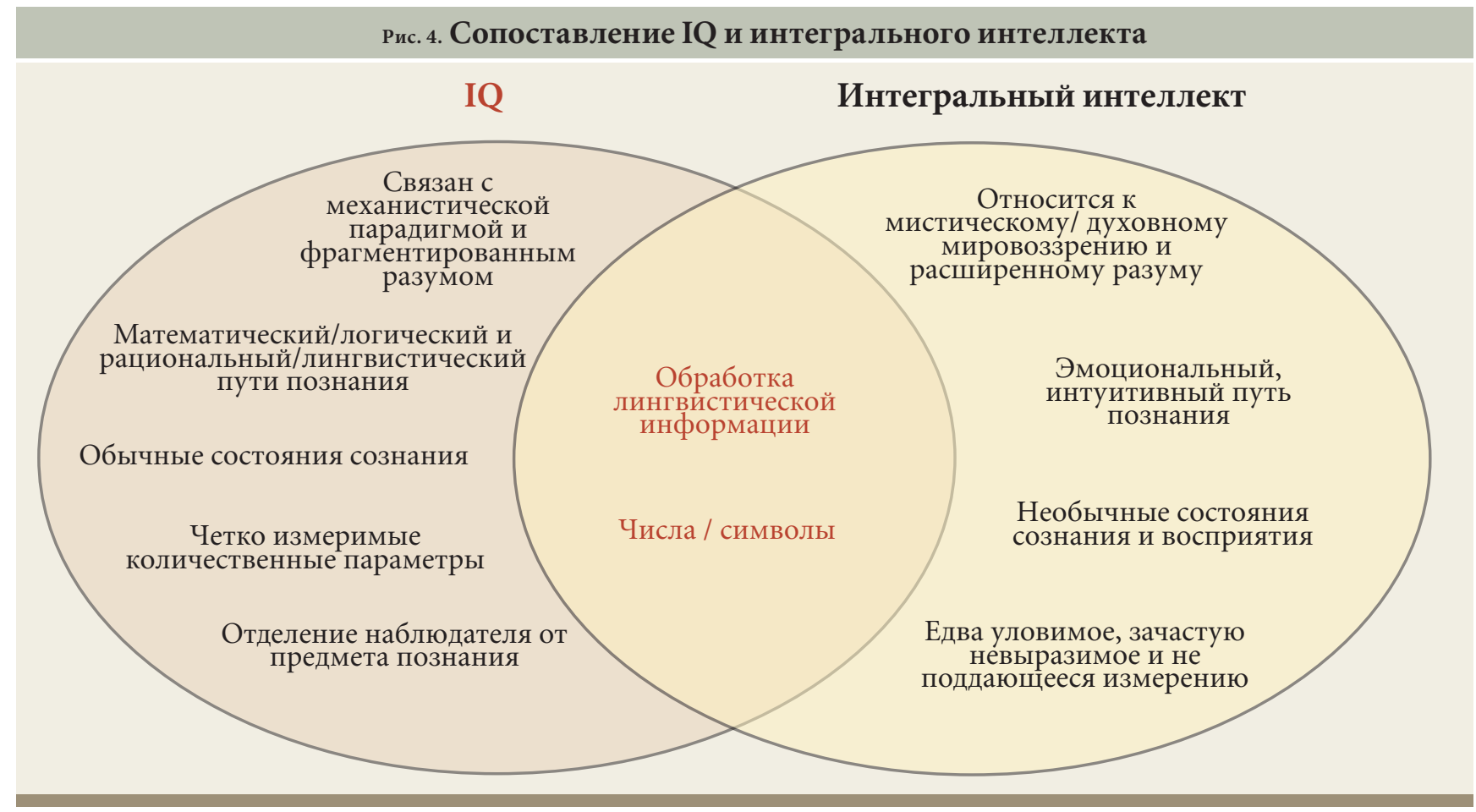


ния и сортировки людей, отличных от реальных объектов, которые могут быть измерены» [30, с. 132].

Используемые глаголы - «материализовать», «измерять» и «доминировать» - указывают на преобладание критического/рационального пути познания и отражают патриархат и механистическую парадигму. Оусу-Бемпа и Хауитт [30] доказывают, что западная концепция самотождественности работает так же, «как аппарат для кодирования и категоризации». Поэтому концепция IQ - западная эпистемная конструкция, которая укрепляет концептуализацию отделенного, диссоциированного «Я» и работает в рамках критических/рациональных путей познания, т.е. фрагментированного разума. Парадигматические и социально детерминированные характеристики Запада породили концепцию IQ. В конечном счете интегральный интеллект, возникающий из мистического/духовного мировоззрения, несовместим с этой конструкцией «Я» и разума.

Теория IQ в итоге есть производная от механистической парадигмы: сингулярное, измеримое, математическое, кодифицированное представление величины уединенного разума, где атомистический, индивидуализированный и фрагментированный интеллект может быть измерен, обозначен числом и таким образом овеществлен. Фокусировка внимания таких теоретиков, как Йенсен, Айзенк, Хернстайн и Мёрри, на измерении интеллекта ограничивает дискуссию уровнем анамнеза. В профессиональной полемике встречается критика, затрагивающая преимущественно социальный уровень (природа против воспитания).

Анализ в этой работе теории IQ и выдвижение на первый план нескольких важных дискуссий обеспечивают выявление некоторых существенных различий между IQ и интегральным интеллектом. Это резюмировано на рисунке 4, который показывает, что у таких концепций есть небольшая область пересечения. Интуитивные впечатления могут проявляться как лингвистические или даже числовые образы [17], но другие связи минимальны. Следует признать, что там, где доминирует IQ, интуитивное и духовное преуменьшаются или полностью игнорируются.

Обратимся теперь к описанию и анализу некоторых других релевантных конструкций интеллекта, имеющих больше общего с интегральным интеллектом.

\section{Системные теории интеллекта и интегральный интеллект}

Одна из наиболее ярко выраженных точек зрения в дискуссиях по вопросам интеллекта принадлежит Стернбергу, который находит, что настало время «выйти за пределы общепринятых теорий интеллекта» [25, с. 73]. Причина в том, что эти теории неполны: «самое существенное препятствие на пути продвижения вперед представляют корпоративные интересы, как в академических кругах, так и в мире тестирований. Психологам теперь предстоит выйти за пределы общепринятых представлений об интеллекте; для этого нужна только воля» [там же].

Существенно, что человеческую волю- область, которую столь неадекватно описывает механистическая наука о разуме, - Стернберг признает основополагающей. Человеческая воля - это самосознание на первом личностном уровне: персональный субъективный внутренний мир. Рекомендация Стернберга обращает внимание на сдвиг господствующей теории интеллекта в направлении признания этой сферы интенций в человеческом познании.

Все же воли не достаточно. Анализ Стернберга остается на втором уровне CLA, будучи ограничен обсуждением социальных и институциональных факторов. Подобно многим теоретикам, выходящим за рамки идеи IQ, Стернберг не бросает вызов цивилизационным и парадигматическим предположениям научного материализма и фрагментированного разума. Он не обращается к внутренним надличностным и духовным измерениям разума. Система CLA позволяет исследовать более глубокие уровни, неявно заложенные в дискурсе, которые часто остаются не осознанными исследователями и поэтому невидимыми для «воли».

Далее мы обратимся к некоторым новым теориям, которые бросают вызов общепринятым. Как будет показано, эти системные теоретики предлагают модели интеллекта, ставящие под вопрос основы рациональной концепции ментальной способности, или g-фактоpa [7]. Их теории не обязательно проблемно-зависимы и могут охватывать более одной области когнитивной деятельности. Речь идет о следующих системных теориях: «эмоциональный интеллект» $[12,13]$, «внутриличностный интеллект» $[10,31]$, «креативный интеллект» [15] и «мудрость» [14].

На рисунке 5 изображены вышеназванные четыре системные теории. Цель состоит в том, чтобы определить, до какой степени они - по сути представляющие собой часть границы общепринятой теории интеллекта - пересекаются с концепцией интегрального интеллекта. Вторая цель состоит в том, чтобы попытаться идентифицировать цивилизационные и парадигматические предрасположенности этих четырех теорий/концепций. Последняя задача - определить, создают ли рассматриваемые четыре представления об интеллекте все вместе новое пространство в пределах общепринятого дискурса, на котором могли бы

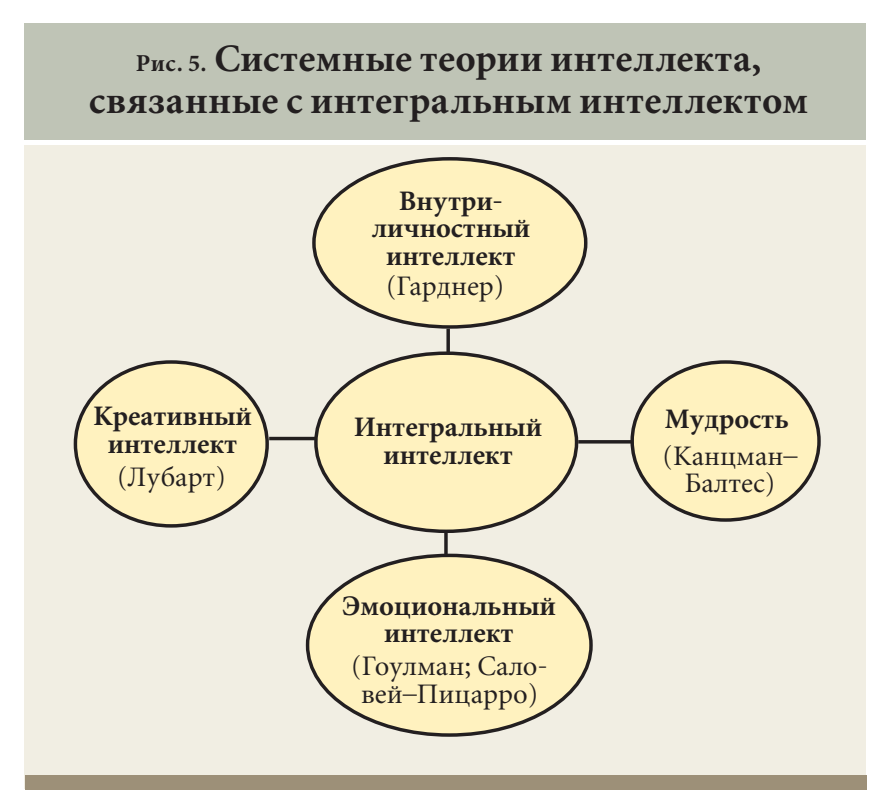

10

Форсайт | № 4 (4) 2007 
инкорпорироваться мистические представления, подобные интегральному интеллекту.

\section{Внутриличностный интеллект (Гарднер)}

Внутриличностный интеллект - это «способность формировать точную, правдивую модель себя и использовать ее для эффективной деятельности в жизни» $[11$, c. 9]. Можно отметить, что глаголы, выражающие познание, неявно помещают теорию Гарднера в рамки критического/рационального мировоззрения; очевидно, что критические/рациональные пути познания ставятся по важности выше фактических внутренних когнитивных состояний. Сознательный разум «формирует» в индивидууме контролируемую модель самого себя - «точную, правдивую» - с целью эффективной деятельности в жизни. Моделирование - типично научное, аналитическое, интеллектуальное усилие. Как и у эмоционального интеллекта Саловея и Пицарро (см. ниже), внутренний мир и его эмоциональное или интуитивное восприятие помещены в нижнее царство, в подчинение эго. Личные внутренние когнитивные состояния управляют надличностным внутренним миром - в противоположность надличностным теориям, например Уилбера [22] и Хокинса [32]. Таким образом, интегральный интеллект (мистическая духовность) и внутриличностный интеллект Гарднера (критическая рациональность) вырастают из различных мировоззрений.

И все же связь между внутриличностным и интегральным интеллектами очевидна: оба требуют внутренних процессов и включают интуитивные, эмоциональные и духовные компоненты. В концеп- ции Гарднера имеется краткое упоминание о том, что «духовный интеллект» может быть «подходящим кандидатом для восьмого интеллекта», несмотря на проблему культурного расхождения концепций духовного и морального [11, с. 46]. Однако в своей первоначальной теории Гарднер [10] не делает явной ссылки на расширенный разум, экстрасенсорный или мистический опыт.

Синтез концепций внутриличностного и интегрального интеллекта может состояться, если в будущем теория интегрального интеллекта заслужит некоторое доверие академических кругов и станет эпистемологически более изощренной. Таким образом, там, где Гарднер [11] и его последователи помещают инструменты и методы, укрепляющие позиции внутриличностного интеллекта, процесс потенциально может быть усилен за счет целенаправленного включения концепции расширенного разума и методов, которые подчеркивают необычные состояния сознания и восприимчивости ${ }^{9}$. Например, Ширер пишет, что основная функция внутриличностного интеллекта - это «руководство принятием решений на жизненном пути человека. Навыки внутриличностного самоуправления требуются пилотам, полицейским, писателям и преподавателям» [33]. Дополнительный информационный вклад расширенного разума мог бы дать огромную выгоду в таких карьерах и в принятии решений на жизненном пути, как отмечено в основных операциях интегрального интеллекта (табл. 1).

Схема на рисунке 6 демонстрирует большую общность между внутриличностным интеллектом Гарднера и интегральным интеллектом. Главное различие кроется в недостаточном исследовании Гарднером надличностного, мистического и сверхъестественного

\section{Рис. 6. Сопоставление интегрального интеллекта с внутриличностным}

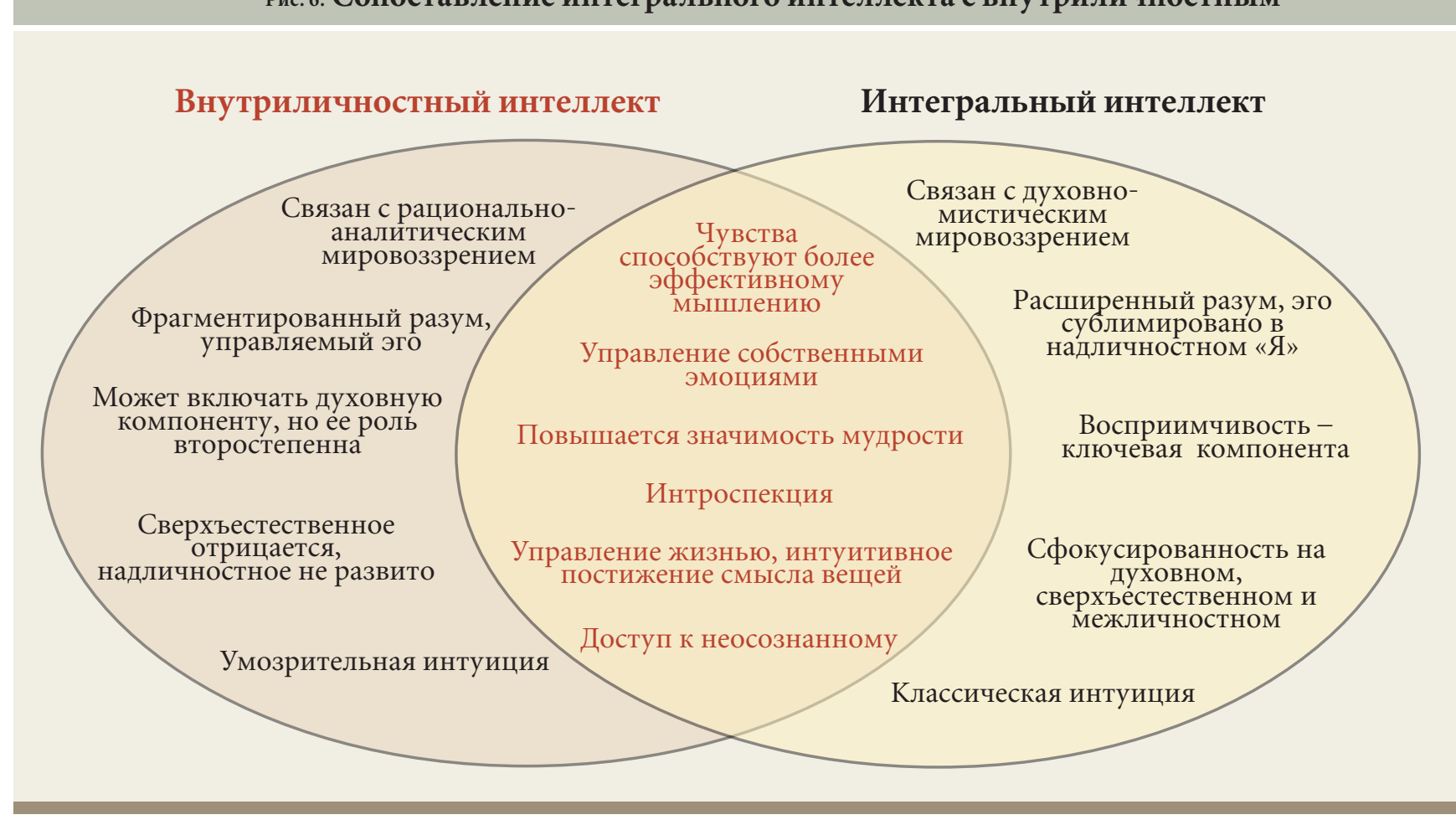

${ }^{9}$ Восприимчивость - это открытое состояние разума, которое дает возможность получения мыслей или идей от тонких уровней сознания и от «внешних» источников за пределами мозга. 
компонентов внутриличностного. Это упущение, скорее всего, возникло из-за парадигматических ограничений со стороны современных академических кругов, которые опираются на критическое/рациональное мировоззрение и западную эпистемологию.

\section{Эмоциональный интеллект (Саловей и Пицарро)}

Дебаты по эмоциональному интеллекту привлекают внимание как в академических кругах, так и на популярном уровне. Обсуждение сосредоточено главным образом на научных взглядах Саловея и Пицарро [13], тогда как популистская версия теории, предложенная Гоулменом [12], отходит на второй план.

Согласно определению Саловея и Пицарро, эмоциональный интеллект - это «способность воспринимать и выражать эмоции точно и адаптивно, способность понимать эмоции и эмоциональные знания, способность использовать чувства для помощи мышлению и способность управлять эмоциями в себе и других» $[13$, с. 263].

Прежде всего о путях познания: глаголы указывают, что интеллектуальное здесь доминирует над эмоциональным. Фраза «воспринимать и выражать эмоции точно и адаптивно» указывает на приоритет вербализации эмоций («выражать»), а это критический/рациональный путь познания. Наречие «точно» предполагает, что управляемый сознательный разум эго - руководит процессом. То, что процесс осуществляется «адаптивно», указывает на цель - осознанную манипуляцию эмоциями. Хотя это не обязательно означает, что в любой первичной эмоции надо искать скрытый «смысл». Важно, что классическая интуиция включает тонкие чувства, «женские» качества и иногда метафизические смыслы. В модели Саловея и Пицарро нет никаких признаков, указывающих на необходимость сознательного разума, чтобы слушать «послания» эмоции, он просто задействует эмоции в соответствии с желаемыми результатами («управлять эмоциями» и «использовать чувства, чтобы помочь мышлению»). Особо следует подчеркнуть, что не предлагается никакого различия между эмоциями и интуицией.

Итак, теория Саловея и Пицарро отводит человеческому эго доминирующую роль, что идет вразрез с надличностным дискурсом, в котором эго рассматривается как нечто менее мудрое и развитое, нежели надрациональный разум [22, 32]. Таким образом, рассмтриваемая модель неявно переворачивает иерархию путей познания, представленную в значительной степени надличностной теорией, помещая интеллектуальное над эмоциональным/интуитивным. По этой причине данная концепция остается частью критического/рационального мировоззрения.

Есть другие специфические пересечения между эмоциональным и интегральным интеллектом. Вот что можно отметить, принимая во внимание характеристики эмоционального интеллекта по Саловею и Пицарро.

Восприятие эмоции. Интегральный интеллект охватывает осознанное восприятие эмоционального и интуитивного. Эмоциональный интеллект, в свою очередь, включает в себя понимание аффективных аспектов когнитивных способностей. В частности, восприимчивость влечет за собой процесс выявления и расшифровки аффективных познаний, поскольку интуитивные процессы часто охватывают сферу эмоционального. Можно поразмышлять о том, что индивидуум с сильным эмоциональным интеллектом был бы лучше осведомлен об этой стадии. Кроме того, любой тренинг, развивающий восприимчивость, вероятно, вызовет улучшение эмоционального/аффективного понимания и, как следствие, эмоционального интеллекта.

Использование эмоций для помощи мышлению. Это положение включает «способность человека принимать в расчет чувства при рассуждении и решении проблем» $[13$, с. 264]. Сюда же относится то, «как эмоции могут использоваться для повышения эффективности принятия решения и творческих усилий... (и) эмоции также могут ранжировать по приоритетам когнитивную систему, чтобы привлечь внимание к тому, что более важно...» [там же]. Здесь просматриваются очевидные пересечения с основными операциями интегрального интеллекта (табл. 1): оценкой и выбором, диагностикой, предвидением, креативностью и инновациями. В концепции эмоционального интеллекта эмоции могут служить повышению эффективности мышления, в то время как аффективная интуиция может задействоваться в основных операциях интегрального интеллекта.

Для повышения доверия - и интереса - к эмоциональному и интуитивному мышлению, как они понимаются в интегральном интеллекте, требуется эмоциональный интеллект. Причем такое доверие и интерес могли бы способствовать и ему. Повышение восприимчивости к чувствам обеспечивает также появление большего объема когнитивных данных.

Понимание эмоции. Саловей и Пицарро определяют это как «способность понимать эмоциональную информацию, а также то, как эмоции объединяются и развиваются в ходе эволюции отношений, и ценить такие эмоциональные смыслы» [13, с. 264]. Как было отмечено, интегральный интеллект потенциально может способствовать пониманию эмоций. Однако тонкости этого процесса, вероятно, будут лучше усвоены в индивидуальных попытках задействовать интегральный интеллект.

Управление эмоциями. Это - «способность открываться чувствам» и «модулировать их в себе» таким образом, чтобы обеспечивать «личностное понимание и рост» [там же]. В случае интегрального интеллекта восприимчивость будет потенциально способствовать открытости к чувствам. Следствием может стать модуляция в себе чувств и эмоций, хотя, как здесь уже отмечалось, не это является непосредственной целью развития интегрального интеллекта, а личностное понимание и рост (см. табл. 1 и 2).

Еще одна сильная связь между эмоциональным и интегральным интеллектом неявно показана в первой статье Саловея и Майера [34] об эмоциональном интеллекте, где они утверждают, что данная теория стремится предложить модель взаимодействия эмо- 
ций и логического мышления. Это также неявная функция интегрального интеллекта. В надличностной теории Уилбера [22] надрациональное превосходит и включает в себя «более низкие» когнитивные домены, в том числе области рационального и эго. Это подразумевает, что надрациональные уровни сознания требуют главенства над рациональным. Поскольку аффективное является важной частью надрационального (что доказывается в теории интегрального интеллекта), можно предположить, что надрациональное и интегральный интеллект включают высокую оценку аффективных аспектов сознания и того, как они связаны с рациональными.

И все же, несмотря на их обширную терминологию, относящуюся к чувствам, эмоциям и интуиции, на парадигматическом уровне модели как Саловея и Пицарро, так и Гоулмена остаются физикалистскими и основаны на локализации мозговых функций, причем тезисы диссертации Гоулмена гораздо более редукционистские. Идея интуиции не развита, а идея расширенного разума не фигурирует. Представление об эмоциональном интеллекте, таким образом, твердо держится общепринятой материалистической концепции разума.

Несмотря на различия, между эмоциональным и интегральным интеллектом существуют сильные актуальные и потенциальные связи (рис. 7). Аффективные сферы сознания охватывают и духовные/мистические дискурсы, и концепцию эмоционального интеллекта Саловея и Пицарро.

\section{Креативный интеллект (Лубарт)}

Лубарт [15] предложил концепцию креативного интеллекта: представление об интеллекте, который пересекается с интегральным интеллектом, особенно в сфере основной операции креативности и иннова- ции. Идея креативного интеллекта выдвинулась лишь в последние годы, первоначально ее значение принижалось из-за доминирования вербальных, числовых и пространственных когнитивных методов в исследованиях интеллекта. Важная дискуссия идет по вопросу, является ли креативный интеллект независимым или это лишь аспект общего интеллекта [там же]. Лубарт находит, что креативный интеллект играет роль «в любой серьезной теории интеллекта» [15, с. 288].

Определение и использование подобной концепции чрезвычайно сильно варьируется в литературе. Часто она четко не определена и может быть неявно представлена в рамках широких дискуссий о творчестве или интеллекте [15]. Поэтому Лубарт воздерживается от предоставления определения, которое охватывало бы все контексты, но находит, что в смысле интеллектуальных способностей, помогающих творчеству, это «те когнитивные способности, которые непосредственно вовлечены в создание ценной оригинальной работы» [15, с. 284]. Способности, усиливающие креативность, включают метафорическое мышление, способность синтеза, творческий подход к задачам, использование мысленных образов и упражнения, включающие дивергентное мышление [там же]. Из определения Лубарта следует, что ключевым моментом для креативного интеллекта является конкретный результат - выполненная «работа».

Все же возможность влияния расширенного разума на творчество не признается, что совпадает с высказываниями в господствующих дискурсах. В то время как способности, которые выделяет Лубарт, могут, очевидно, вовлекать расширенный разум, он не выводит отсюда никаких предположений. Вместо этого Лубарт отмечает, что «понимание креативного интеллекта включает нечто большее, чем простое перечисление подмножества релевантных интеллектуальных способностей. Креативный интеллект затрагивает

\section{Рис. 7. Сопоставление интегрального интеллекта с эмоциональным}

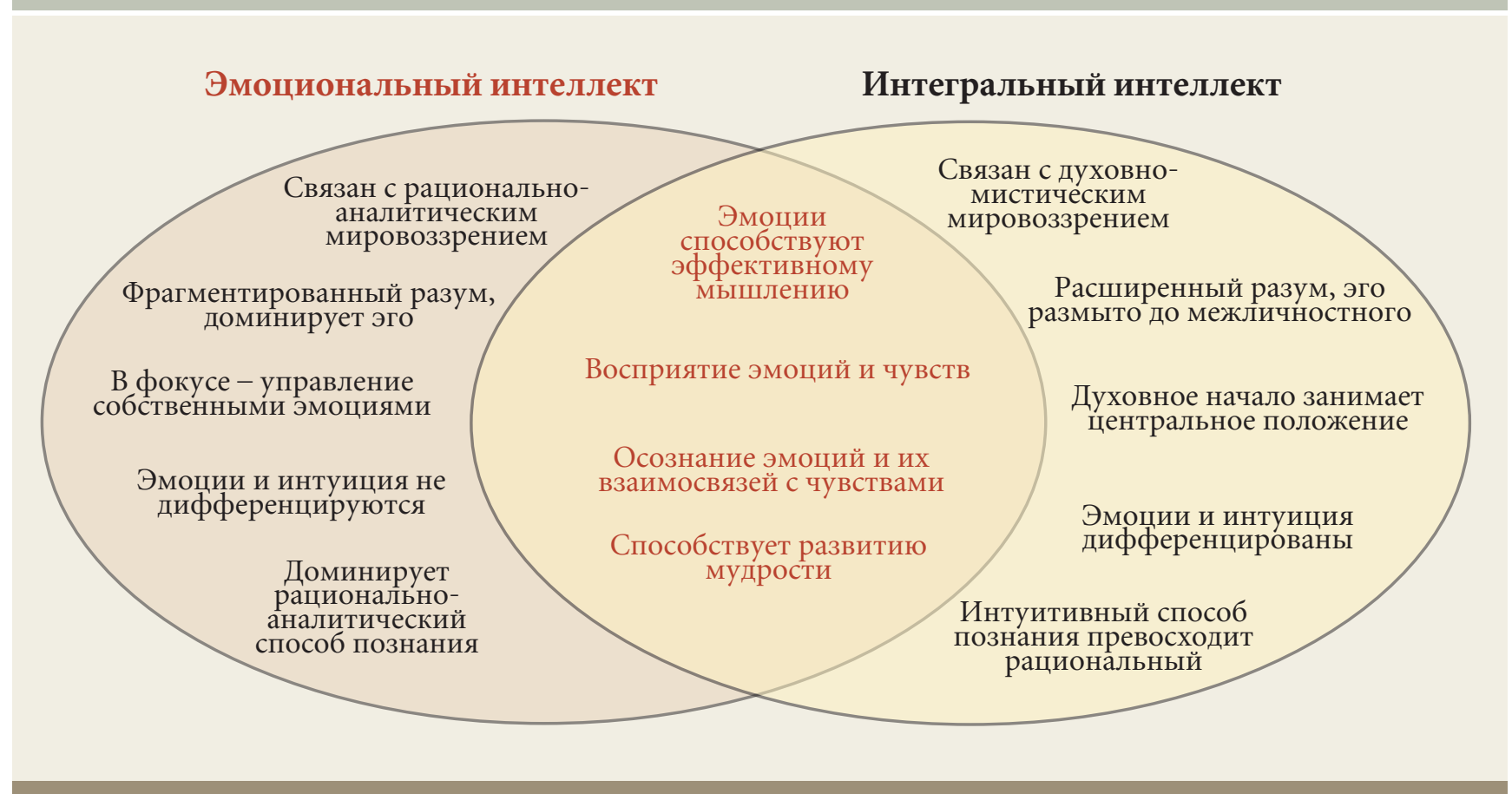


метаспособности, то есть знание о том, как или когда с наилучшим эффектом использовать когнитивные способности в ходе решения задачи» [там же, с. 289].

Термин «метаспособности» предполагает умение проецировать данную конкретную проблему на идеальные средства, применяемые для решения любых творческих задач. Это больше напоминает декартовское самоотражение на интеллектуальном уровне (личный внутренний мир субъекта), нежели надличностный когнитивный метод (надличностный внутренний мир субъекта). Отсутствие мистического аспекта - главное расхождение между креативным интеллектом по версии Лубарта и интегральным интеллектом.

Есть, однако, и пересечения, причем интегральный интеллект в целом потенциально релевантен креативному. Связь между надличностным/мистическим состоянием сознания и креативностью широко обсуждается $[35,36]$, правда в основном теоретиками, находящимися за пределами общепринятого дискурса. Радин отмечает, что творческие люди чаще сообщают о сверхъестественных переживаниях. Так происходит, считает он, потому, что у них меньше «латентных сдерживающих факторов»- они не отсеивают подсознательно столь же большой объем ментальной информации, как менее творческие люди [35, c. 51]. Традиционно, представления о музах и демонах, духах-посредниках, посланиях ангелов или духов предков имели сильное влияние в древних и средневековых культурах (см., например, [37, 38, 39]). Концепция интегрального разума открывает возможность получения воздействий от таких источников, как морфогенетические поля [36], коллективные поля интеллекта [29, 40] и духовные/сверхъестественные источники [37]. Например, писатель Ричард Бах утверждает, что он не сам писал свой бестселлер «Чайка по имени Джонатан Ливингстон», а что роман «прошел «через него» [41, с. 103]. Хотя для объяснения творческого начала и нет нужды обращаться к таким сущностям, они совместимы с теорией интегрального интеллекта.

На периферии общепринятого дискурса сильные связи с креативностью имеет концепция потокового «слияния действия и сознавания» [42, с. 183]. «Поток» представляет собой необычное состояние сознания, которое сходно с понятием восприимчивости, с его слиянием наблюдателя и наблюдаемого.

Названные теоретики имеют тенденцию оставаться за рамками общепринятой теории интеллекта, которая, как правило, отвергает мистические концепции. В самом деле, такой эмпирик, как Стернберг [6], полагает - о чем говорится в начале его статьи, - что эта область заражена ссылками на мистику.

В подобного рода духовных, интуитивных и креативных концепциях разума часто считается, что простое накопление данных и знаний имеет ограниченные возможности в качестве средства обеспечения глубокого понимания $[15,43]$. Древнекитайский мистик Лао Цзы выразил это афоризмом: «Тот, кто говорит, не знает» [44]. Высокая эрудиция в данной сфере может приводить к ментальной косности в применении знаний и «предубеждениям и фиксации на легкодоступных, но неадекватных знаниях» $[15$, c. 285]. Как и креативное мышление, интегральный интеллект может помочь обойти ограничения, порождаемые прямолинейными подходами к решению проблем.

Как показано на рисунке 8, креативный интеллект Лубарта и интегральный интеллект имеют множество пересечений. И все же модель Лубарта является отражением западной эпистемологии, игнорирующей мистические компоненты и расширенный разум. Иначе обстоит дело при обсуждении темы за пределами профессионального круга. Представления о расши-

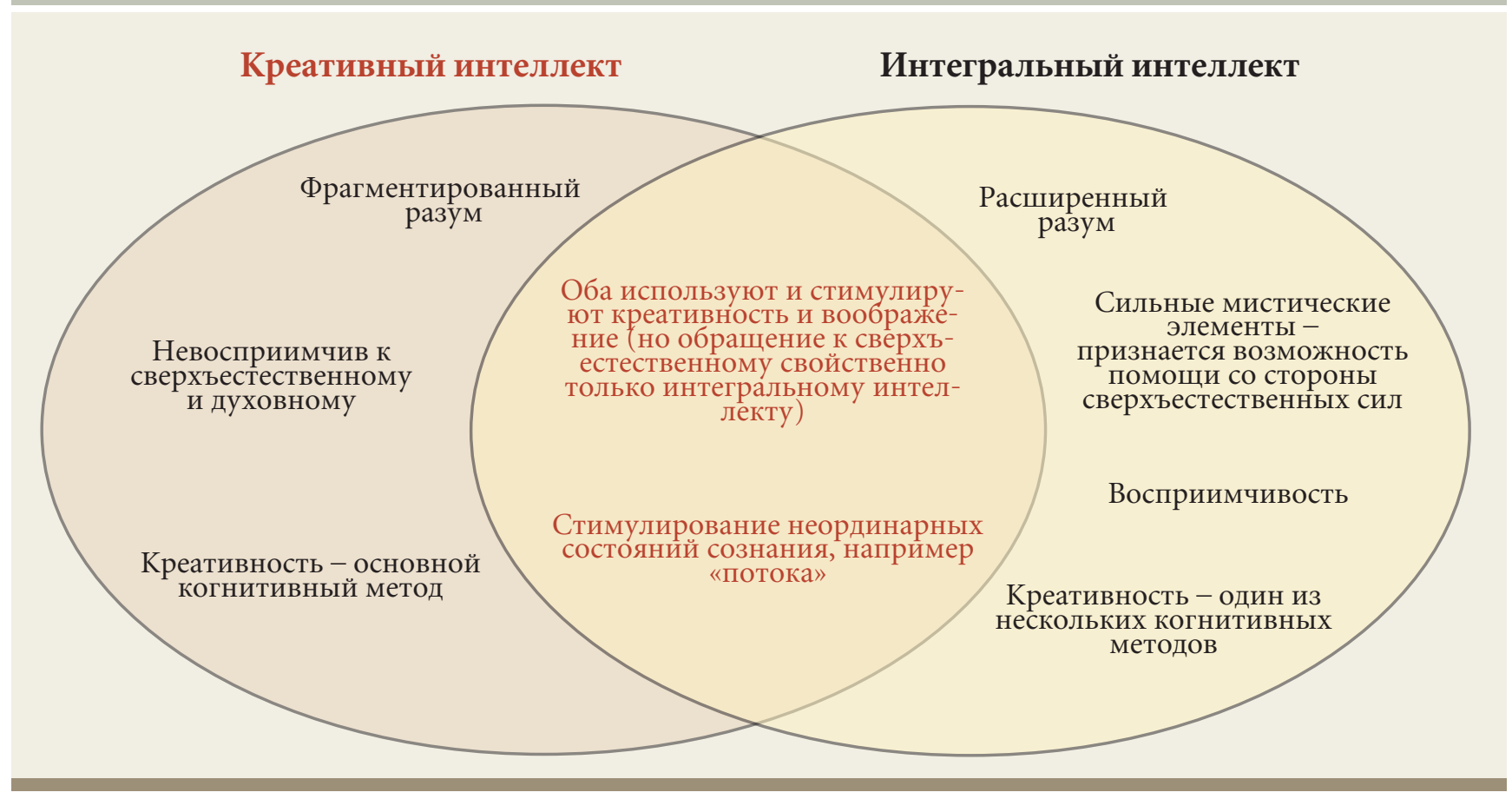


ренном разуме и царстве сверхъестественного могут потенциально развить идею креативности, главным образом посредством восприимчивости и необычных состояний сознания.

\section{Мудрость (Канцман и Балтес)}

Мудрость является итогом эффективного применения интегрального интеллекта, и поэтому мудрость и интеллект часто рассматривают в тесной взаимосвязи [6]. Концепция мудрости как аспект интеллекта начала завоевывать позиции в последние десятилетия, когда стала шире известна теория интеллекта $[6,14]$. По определению Канцмана и Балтеса, мудрость - это «экспертные знания о фундаментальной прагматике жизни» [там же, с. 332], одно из «многих лиц» интеллекта [там же, с. 329].

Упомянутая фундаментальная прагматика рассматривает «знание важных и трудных аспектов смысла жизни и поведения, включая планирование жизни (например, кто какую цель и в какой ситуации должен преследовать), управление жизнью (например, как быть с такими социальными проблемами, как самоубийства), оценку жизни (например, как осмыслить наш прошлый опыт). К мудрости относится и общее знание о человеческой природе, которое выходит за пределы данного культурного контекста и исторического периода, а также детальное знание о переменах в смысле жизни и поведении» [там же, с. 333].

Здесь имеется значительное пересечение с основными операциями и конечными состояниями интегрального интеллекта - особенно с личными и социальными трансформациями, интегральной перцепцией, оценкой и выбором, диагнозом и самой мудростью.

Нелегко дать определение мудрости. Она может быть описана как аспект индивидуальности, аспект развития, «постформальное диалектическое мышление» или "расширенная форма интеллекта» [там же, c. 331]. Для Стернберга мудрость - это вид практического интеллекта: «Мудрость проявляется, когда практический интеллект... применяется для максимизации не только собственных или чьих-то индивидуальных интересов, а скорее, балансирования разнообразных индивидуальных интересов (внутриличностный план) с интересами других людей (межличностный план) и иными аспектами контекста, в котором протекает жизнь (экстраличностный план), например города, страны, окружающей среды или даже Бога» [цит. по: 14, с. 332].

Глаголы нейтральны относительно мировоззрения. Балансирование личного интереса с интересами других могло активизировать как критические/рациональные, так и интуитивные пути познания. Глагол «применяться» выделяет практическую природу мудрости, которая представляет собой не только интеллектуальное, но прикладное знание [6], и он опять же не отдает предпочтения какой-то определенной когнитивной модальности.

Примечательна догадка Канцмана и Балтеса: «Что отличает мудрость от (практического) интеллекта - это ее ориентация на максимизацию общего блага, а не индивидуального благосостояния» [14, с. 332]. Этим она уподобляется интегральному интеллекту, который охватывает человеческие/социальные и космические аспекты и предполагает признание и уважение чего-то большего, чем эго. По модели Канцмана и Балтеса, мудрость подразумевает сильный контекст социального уровня, в то время как интегральный интеллект дополнительно расширяет его на космический или духовный уровень.

Подобно трем «интеллектам», рассмотренным выше, мудрость, в определении Канцмана и Балтеса,

\section{Рис. 9. Сопоставление мудрости и интегрального интеллекта}

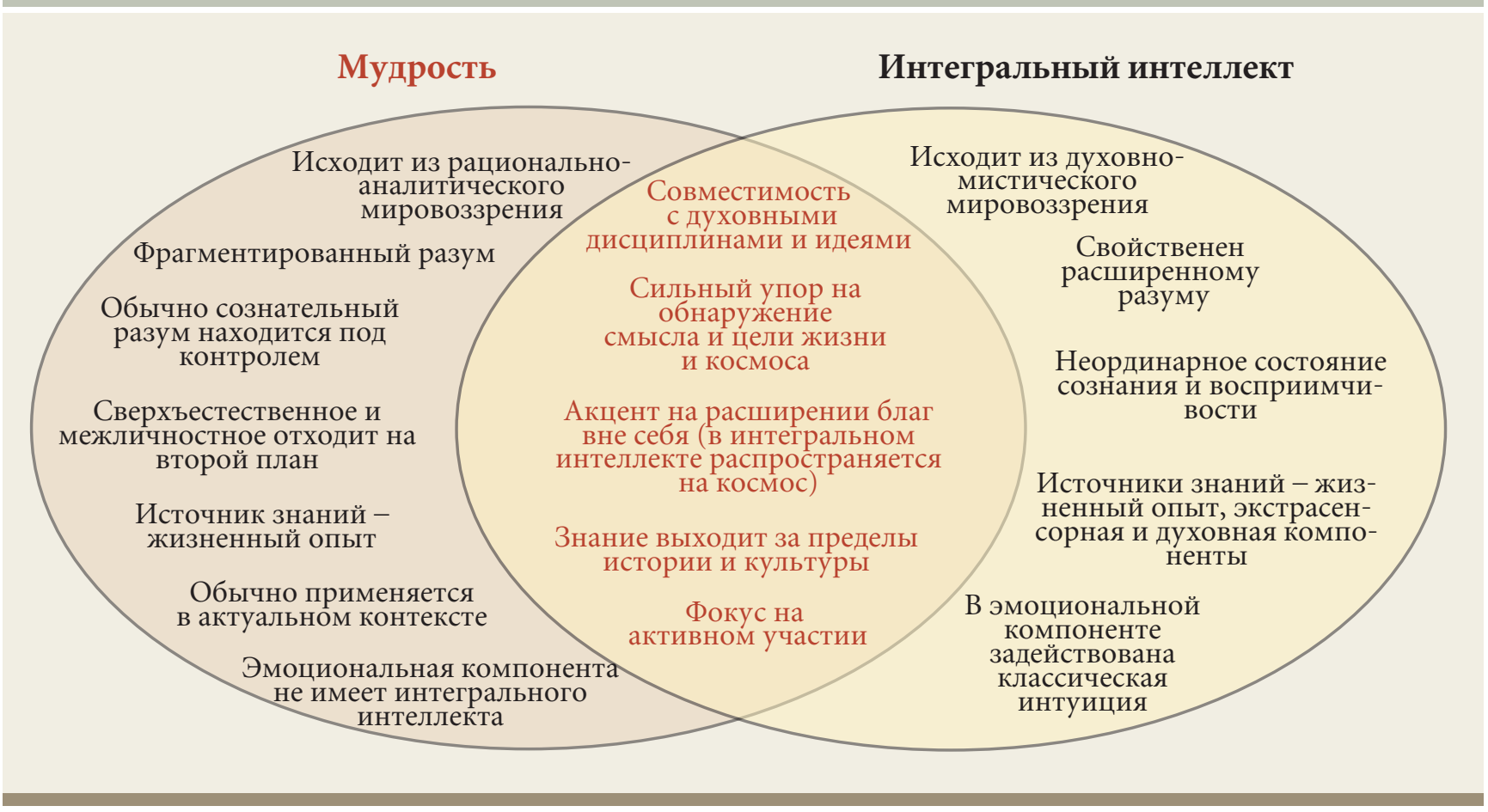


не содержит элементов расширенного разума, хотя одиночная ссылка на духовную концепцию - не вполне ясное упоминание «Бога» в процитированном определении Канцмана и Балтеса - имеется. В научном мейнстриме мудрость обычно рассматривают как продукт сознательного рефлексивного процесса [6] и не прибегают к помощи интроспективных средств для возбуждения необычных состояний сознания и восприимчивости, как в случае с интегральным интеллектом.

Стоя на мировоззренческих позициях современного научного сообщества, Канцман и Балтес избегают упоминать о царствах сверхъестественного и надличностного. И все же эти царства не являются несовместимыми с другими представлениями о мудрости, пришедшими от цивилизаций с мистическим мировоззрением. В туземных обществах есть ссылки на молитвы, медитации и получение знаний от духов предков, что зачастую ассоциируется с мудростью [37, $38,39]$. В древнегреческой культуре оракулы и предсказатели считались мудрыми, и в их умы, как полагали, вселялась мудрость богов $[29,45]$. Касаясь в своих представлениях мудрости, туземные и древние культуры часто не отделяют ее от сверхъестественного.

Существенным общим моментом в теории интегрального интеллекта и концепции мудрости Канцмана и Балтеса является то, что в последней мудрость представляется как «интеграция интеллектуальных, объективных или рациональных методов познания с эмоциональными, субъективными или толковательными методами понимания» [14, с. 337]. Применение интегрального интеллекта, вероятно, потребует всех этих путей познания. Как уже отмечалось, в надличностной теории Уилбера [22] надрациональные сферы развития человеческого сознания превосходят и включают в себя рациональные. И все же концепция Канцмана и Балтеса не включает надличностного или иерархии, которая придавала бы ценность какому-либо определенному пути познания. При сравнении с интегральным интеллектом различие обнаруживается в том, что последний в большей степени прорабатывает эмоциональное/аффективное, позволяя включить классическую интуицию и тонкие аспекты расширенного разума.

Наконец, Канцман и Балтес подчеркивают, что мудрость имеет отчетливо практический, а не чисто когнитивный характер, будучи направлена на «оптимальную человеческую деятельность» [там же, с. 340-341]. В теории интегрального интеллекта это соответствует акценту на «совместности деятельности», почерпнутому из коллективистского подхода к надличностному в теории Феррера [46].

Как видно из рисунка 9, между мудростью и интегральным интеллектом обнаруживается много общего, даже несмотря на то что Канцман и Балтес не обращаются к понятиям сверхъестественного и надличностного. Их избегание повторяет три предыдущие системные теории, поскольку все они происходят от западной эпистемологии и критического рационального мировоззрения, что налагает ограничения на обсуждение мистических концепций.

По мере развития литературы, имеющей дело с концепцией мудрости, теория интегрального интеллекта

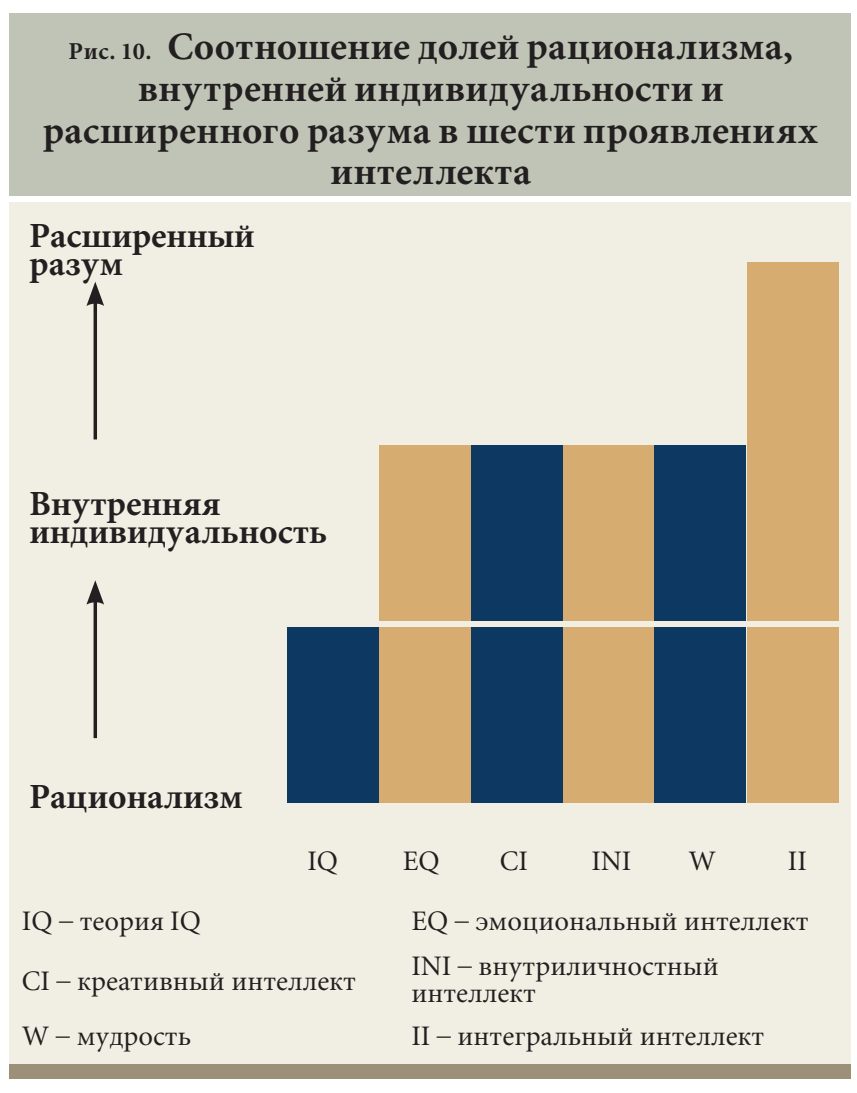

могла бы объединиться с теорией мудрости и обеспечить более глубокое понимание последней. В западной культуре отмечается тенденция отклонять либо преуменьшать другие цивилизационные представления о мудрости, которые включают в себя сверхъестественные и надличностные элементы. Углубление понимания интегрального интеллекта может изменить это отношение и позволить западной социальной науке по достоинству оценить расширенное определение мудрости.

\section{Теория интеллекта, интегральный интеллект и будущее}

Итак, я поместил интегральный интеллект в поле цивилизационных и эпистемологических перспектив, сопоставив его с концепцией IQ и рядом более прогрессивных теорий интеллекта. Интегральный интеллект, безусловно, исходит из альтернативных парадигмы и мировоззрения и поэтому не затрагивается в широких дискуссиях об интеллекте. Теперь рассмотрим, может ли в обозримом будущем интегральный интеллект занять место в господствующем дискурсе по интеллекту, и оценим потенциальные выгоды такого поворота дел.

Сказанное выше позволило охарактеризовать отношения между интегральным интеллектом и различными концепциями в рамках теории интеллекта. Теория IQ стремится исключить все, кроме тех концепций интеллекта, которые четко верифицируются статистически и очерчиваются «рационально». В то же время теория множественного интеллекта Гарднера $[10,11]$ с его концепцией внутриличностного интеллекта и другие три рассмотренные в этой работе теории оказались полезны для создания основ структуры, позиционирующей интегральный интеллект среди системных теорий интеллекта. 
Существуют между тем некоторые фундаментальные различия между интегральным интеллектом и доминирующим научным дискурсом.

Теория IQ и системные теории в рамках доминирующего дискурса содержат элементы, которые создают проблемы на пути признания и определения места интегрального интеллекта. Стандартизированные тесты на интеллект, по сути, являются «письменными экзаменами» [10] и проводятся в обычных состояниях сознания. Например, в упомянутых выше тестах WAIS-3, которые «разумно репрезентативны» для тестов IQ в целом [23, с. 6], нет даже попытки получить доступ к необычным состояниям разума, которые часто связываются с восприимчивостью и, таким образом, с интегральным интеллектом [29, 40, 47]. Кроме того, WAIS-3 не тестирует какие-либо когнитивные методы, основные операции или конечные состояния, связанные с интегральным интеллектом, в частности экстрасенсорную восприимчивость, духовное понимание, мудрость, интуитивное схватывание глубоких и трансцендентных смыслов, связь с духовными сферами и знаниями и т.д. Как и характерно для современных тестов интеллекта, интегральный интеллект в WAIS-3 играет незначительную роль, а то и вовсе не учитывается, ни как объект когнитивного измерения, ни как метод.

Многие теоретики, как и в случае с четырьмя описанными выше теориями интеллекта, выходя в своих построениях за рамки теории IQ, как правило, лишь расширяют в горизонтальном направлении концепцию фрагментированного разума. Это делается путем добавления таких измерений, как: латеральное мышление [48], коллективный интеллект [24, 49], инференционная интуиция [50, 51]; «гражданский интеллект» [52] или различные нелинейные компоненты, подобные «нечеткой логике» Коско [53]. Нет никакого расширения в вертикальном направлении, в область надрационального. За исключением логики Коско, указанные теории не обращаются к взглядам мировоззренческого уровня либо рассматривают интеллект лишь в цивилизационном аспекте. Они происходят из механистической парадигмы, которая не учитывает концепцию интегрального интеллекта, поскольку биологический, локализованный и фрагментированный интеллект лежит в пределах той парадигмы.

Существенно доминирование в начале и середине двадцатого столетия подхода, сконцентрированного на индивидуальных различиях, поскольку он имел дело только с анамнезом. Из-за этого влияние социальных факторов и окружающей среды на развитие интеллекта не получало признания. Этому, безусловно, способствовало господство индивидуалистических подходов Гальтона, Бине и Пиаже вплоть до 1950-х годов [2].

Больший упор Выготского на культурные факторы помог вернуть внимание к этой проблеме [2, 26]. Тем не менее внимание распространилось лишь на сферу социального. Системные теории, включающие в себя внутриличностный интеллект, эмоциональный интеллект, мудрость и креативность, охватили также внутренние области разума. Но ни одна из концепций не затрагивает надличностное. Здесь как раз та сфера, на которую в предстоящие годы интегральный интеллект может распространить теорию интеллекта, если сохранится тенденция к признанию большего значения внутренних факторов. Это, однако, требует парадигматического сдвига, поскольку, как уже отмечалось, господствующая теория интеллекта все еще погружена в мировоззрение критической рациональности, тогда как интегральный интеллект происходит из мистического/духовного мировоззрения.

Итак, рациональные методы отсылают нас к критической рациональности и предпочтительным для нее путям познания; индивидуальный внутренний мир соответствует сфере личного субъективного внутреннего мира согласно модифицированной четырехсекторной модели Уилбера [22], а расширенный разум включает субъективный надличностный внутренний мир.

Если интегральный интеллект вольется в господствующий научный дискурс, это может принести ряд выгод. Во-первых, в обсуждение будут включены понятия надличностного и нелокального разума, что позволит расширить круг рассматриваемых гипотез и объяснений. Концепция интегрального интеллекта потенциально добавляет вертикальное измерение к теории интеллекта - когнитивную способность, которая выходит за рамки психометрических и системных теорий. Об этом свидетельствует постоянный поток подтверждений того, что интегральный интеллект, в отличие от общепринятых теорий, включает в себя расширенный разум (рис. 10). Во-вторых, интегральный интеллект может подорвать господствующий дискурс и бросить вызов часто не исследованным допущениям, на которых этот дискурс основывается - в частности, о том, что сознание сконцентрировано в мозге и является эволюционным эпифеноменом. Наконец, интегральный интеллект открывает альтернативные цивилизационные перспективы, поскольку в значительной части эта концепция взята из восточной и туземной культуры и философии.

\section{Заключение}

Хотя конкретные теории, рассмотренные выше, представляют лишь малую долю современной общепринятой теории интеллекта, они были подвергнуты исследованию, поскольку представляют собой часть современных рубежей теории интеллекта - это те концепции, которые раздвигают границы признаваемого. Главный выявленный здесь факт состоит в том, что такие границы остановились сейчас прямо перед надличностными факторами. Основная причина кроется в схеме, согласно которой общепринятая теория интеллекта существует в рамках механистических концепций локализованного в мозгу сознания, которые лежат в основе современной когнитивной психологии и науки о разуме в целом. Рассмотрение концепции интегрального интеллекта поможет расширить рамки этого дискурса. 
1. Fromberg D. The Intuitive Mind and Early Childhood Education. In: Torff B., Sternberg R. (Eds.) Understanding and Teaching the Intuitive Mind. Mahwah: Lawrence Erlbaum Associates, 2001. PP. 93-114.

2. Sternberg R., Lautry J., Lubart T. Where Are We in the Field of Intelligence, How Did We Get Here, and Where Are We Going? In: Sternberg R., Lautry J., Lubart T. (Eds.). Models of Intelligence: International Perspectives. Washington: American Psychological Association, 2003. PP. 3-25.

3. Anthony M. Integrated intelligence: classical and contemporary depictions of mind and intelligence and their educational implications. London: Sense Publishers, 2007.

4. Inayatullah S. Questioning the Future: Futures Studies, Action Learning and Organizational Transformation. Taipei: Tamkang University Press, 2002.

5. Plucker J. History of Influences on the Development of Intelligence Theory and Testing. 2003. www.indiana.edu/\%7Eintell/map. shtml.

6. Sternberg R. Wisdom, Intelligence and Creativity Synthesized. Cambridge: Cambridge University Press, 2003.

7. Jensen A. The $\mathrm{g}$ factor. The Science of Mental Ability. Westport: Praeger, 1998.

8. Eysenck H. Intelligence: A New Look. New York: Transaction, 2002.

9. Hernstein R., Murry C. The Bell Curve: Intelligence and Class Structure in American Life. New York: Free Press, 1994.

10. Gardner H. Frames of Mind: The Theory of Multiple Intelligences (10th Anniversary Edition). New York: Basic Books, 1993.

11. Gardner H. Multiple Intelligences: The Theory in Practice. New York: Basic Books, 1993.

12. Goleman D. Working With Emotional Intelligence. New York: Bantam Books. 1999.

13. Salovey P., Pizarro A. The Value of Emotional Intelligence. In: Sternberg R., Lautry J., Lubart T. (Eds.). Models of Intelligence: International Perspectives. Washington: American Psychological Association, 2003. PP. 169-181.

14. Kunzmann U., Baltes P. Beyond the Traditional Scope of Intelligence: Wisdom in Action. In: Sternberg R., Lautry J., Lubart T. (Eds.). Models of Intelligence: International Perspectives. Washington: American Psychological Association, 2003. PP. 329-343.

15. Lubart T. In Search of Creative Intelligence. In: Sternberg R., Lautry J., Lubart T. (Eds.). Models of Intelligence: International Perspectives. Washington: American Psychological Association, 2003. PP. 279-292.

16. Anthony M. A genealogy of the western rationalist hegemony//Journal of Futures Studies, v. 11 (1), 2006.

17. Sheldrake R. The Sense of Being Stared At and Other Aspects of the Extended Mind. London: Arrow Books, 2003.

18. Anthony M. Integrated intelligence: The future of intelligence?//Journal of Futures Studies, 8 (2), 2003, pp. 39-54.

19. Anthony M. Education for transformation: integrated intelligence in the knowledge economy and beyond//Journal of Futures Studies, v. 9 (3), 2005, pp. 31-35.

20. Anthony M. Integrated intelligence and the pychospiritual imperatives of mechanistic science//Journal of Futures Studies, v. 10 (1), 2005, pp. 31-47.

21. Targ R., Katra J. Miracles of Mind: Exploring Nonlocal Consciousness and Spiritual Healing. Novato: New World Library, 1999.

22. Wilber K. Sex, Ecology, Spirituality. Boston: Shambhala, 2000.

23. Deary I. Intelligence: A Very Short Introduction. New York: Oxford University Press, 2001.

24. Nash R. Cognitive Habitus and Collective Intelligence//Journal of Educational Policy, v. 20 (1), 2005, pp. 3-21.

25. Sternberg R. Construct Validity of the Theory of Successful Intelligence. In: Sternberg R., Lautry J., Lubart T. (Eds.). Models of Intelligence: International Perspectives. Washington: American Psychological Association, 2003. PP. 55-77.

26. Gardner H., Kornhaber M. L., Wake W. K. Intelligence: Multiple Perspectives. New York: Harcourt Brace College, 1996.

27. Gardner H. Three Distinct Meanings of Intelligence. In: Sternberg R., Lautry J., Lubart T. (Eds.). Models of Intelligence: International Perspectives. Washington: American Psychological Association, 2003. PP. 43-54.

28. Terman L. Intelligence and It’s Measurement//Journal of Educational Psychology, v. 12 (3), 1921, pp. 127-133.

29. Grof S. Beyond the Brain. New York: State University of New York Press, 1985.

30. Owusu-Bempah K., Howitt D. Psychology Beyond Western Perspectives. Leicester: The British Psychological Society, 2000.

31. Gardner H. Intelligence Reframed. New York: Basic Books, 1999.

32. Hawkins D. Power vs. Force: An Anatomy of Consciousness. London: Hay House, 2002.

33. Shearer B. Multiple Intelligences Theory after 20 Years//Teachers College Record, v. 106 (1), 2004, pp. 2-16.

34. Salovey P., Mayer J. Emotional Intelligence. Imagination, Cognition, and Personality. 9, 1990, pp. 185-211.

35. Radin D. Entangled Minds. New York: Paraview, 2006.

36. Sheldrake R., McKenna T., Abraham R. Chaos, Creativity, and Cosmic Consciousness. Rochester: Park Street Press, 2001.

37. Broomfield J. Other Ways of Knowing. Rochester: Inner traditions, 1997.

38. Lawlor R. Voices of the First Day: Awakening in the Aboriginal Dreamtime. Vermont: Inner Traditions, 1991.

39. Murinbata T., Whitehead C. Why Consciousness Conferences Are Not Really Getting Us Anywhere. 2002. www.imprint.co.uk/pdf.

40. Grof S. Psychology of the Future. New York: Suny, 2000.

41. Rowan R. The Intuitive Manager. New York: Berkley, 1991.

42. Czikszentmihalyi M. A Psychology for the Third Millennium. New York: Harper Perennial, 1994.

43. Zohar D. Spiritual Intelligence. London: Cygnus Books, 2000.

44. Jiyu R. (Ed.) The Book of Lao Zi. Beijing: Foreign Languages Press, 1998.

45. Tarnas R. The Passion of the Western Mind. London: Pimlico, 2000.

46. Ferrer J. Revisioning Transpersonal Theory. New York: State University of New York Press, 2002.

47. Braud W. Distant Mental Influence. Charlottesville: Hampton Roads, 2003.

48. de Bono E. Six Thinking Hats. London: Penguin, 1999.

49. Szuba T. Was There Collective Intelligence Before Life On Earth?//World Futures, v. 58, 2002, pp. 61-80.

50. Klein G. The Power of Intuition. New York: Doubleday, 2003.

51. Torff B., Sternberg R. (Eds.). Understanding and Teaching the Intuitive Mind. Mahwah: LEA Books, 2001.

52. Dewey J. Cultivating Society's Civic Intelligence: Patterns for a New «World Brain»//Journal of Society, Information and Communication, v. 4 (2), 1937.

53. Kosko B. Fuzzy Thinking. London: Harper Collins, 1993. 